\title{
Chemical compositions of essential oils from two Artemisia species used in Mongolian traditional medicine
}

\author{
N.Javzmaa1*, Sh.Altantsetseg ${ }^{1}$, S.Shatar ${ }^{1}$, A.Amarjargal ${ }^{2}$ \\ ${ }^{1}$ Institute of Chemistry and Chemical Technology, Mongolian Academy of Sciences, MAS $4^{\text {th }}$ building, \\ Peace Avenue, Bayanzurkh district, Ulaanbaatar 13330, Mongolia \\ ${ }^{2}$ Mongolian University of Khovd, Khovd aimag, Mongolia \\ *Corresponding author: njavzmaa@gmail.com
}

Received: 12 September 2017; revised: 18 January 2018; accepted: 19 January 2018

\begin{abstract}
Essential oils of aromatic and medicinal plants generally have a diverse range of activities because they possess many active constituents that work through a several modes of action. Artemisia, the largest genus of the family Asteraceae, has a number of effects against human and plant diseases. The main purpose of the present study was to investigate chemical compositions of essential oils of two Artemisia species, Artemisia palustris L and Artemisia sericea Weber ex Stechm from the Mongolian steppe zone using gas chromatography and gas chromatography-mass spectrometry. The essential oil of $A$.palustris was characterized by the presence of monoterpene hydrocarbons such as trans- $\beta$-ocimene (59.1\%), cis- $\beta$-ocimene $(11.6 \%)$ and myrcene $(7.1 \%)$, while the oil of $A$.sericea was dominated by the presence of three oxygenated monoterpenoids as 1,8 -cineole $(25.8 \%)$, borneol $(22.5 \%)$ and camphor $(18.8 \%)$ which are used for preparation of a fragrance and medicinal products.
\end{abstract}

Keywords: Artemisia palustris L, Artemisia sericea Weber, $\beta$-ocimene, 1,8-cineole, camphor

\section{INTRODUCTION}

The Asteraceae family is endowed with essential oilyielding plants, in particular, the genus Artemisia occupies a top position for its bio-prospection [1]. The genus consists of a small herbs and shrubs, found in northern temperate regions and comprises of about 500 species from South Asia, North America, and European countries [2]. In Mongolia, 103 Artemisia species have been found [3].

Generally, the species of the genus Artemisia are called as the common names mugwort, wormwood, and sagebrush. Due to the presence of terpenoids and sesquiterpene lactones, the most of the species possess strong aromas and bitter tastes, which discourage herbivores and may have had a selective advantage [4]. The Artemisia species have wide and various applications to the plant and human disease control, as well as in the pharmaceutical industry [5]. Some species are used in Tibetan-Mongolian traditional medicine because they do not only repel helminths of the intestine, but also have antioxidative, anticancer, antiviral and allelopathic activities [3]. In Mongolian traditional medicine, the leaves of A.palustris show the beneficial influence for treatment of skin diseases, while the seeds are useful for treatment of bronchitis and tuberculosis [6]. The aerial parts of A.sericea are used for treatment of pneumonia, inspiratory and gastric diseases [7].

From the previous research, the aerial parts of A.palustris growing in Siberia, Russia have known to contain flavonoids (luteolin, quercetin, hyperozide, cinarozid, and chalcones), coumarin (umbelliferone) and essential oil which mainly consisted of trans- $\beta$-ocimene $(50 \%)$, cis- $\beta$ ocimene $(40 \%)$, myrcene $(2 \%)$ and some sesquiterpenes [10]. The increasing importance of essential oils in various domains of human life (pharmacy, cosmetics, food and beverage industries), especially the essential oil rich in $\beta$-ocimene, has attracted researchers interests to the essential oil A.palustis from the Mongolian flora. There are results described about seed oil of A.palustis growing in Mongolia [9]. However, its essential oil has not been studied yet. The Artemisia species from the Mongolian unexplored flora could be unusual resources of essential oils. To the best of our knowledge, A. sericea has also not been previously investigated for its chemical compositions and in particular, the essential oil.

In the present work we analyzed the chemical compositions of the essential oils of the aerial parts A.palustris and A.sericea occurring in Mongolia and compared them with oils of other Artemisia species to determine their characteristic profile.

\section{EXPERIMENTAL}

Plant material: The aerial parts of A.palustris were collected at the full bloom stage in September 2009, while, A.sericea was harvested at the fruiting stage in August 2008 from the Terelj region of Khentii mountains located in the east of Ulaanbaatar, Mongolia (Table 1). 
Voucher specimens are deposited in the Herbariums of the Institute of General and Experimental Biology of the Mongolian Academy of Sciences.

Preparation of oil: Air-dried aerial parts of each plant species $(70-80 \mathrm{~g})$ were hydrodistilled in the Clevenger type apparatus for $3 \mathrm{~h}$. The essential oil yields of A.palustris were $1.4 \%$, while A.sericea $0.4 \%$, respectively. The essential oils were dried over anhydrous calcium chloride and stored in sealed vials at $4^{\circ} \mathrm{C}$ before analysis.

Gas chromatography (GC) - gas chromatography and mass spectrometry (GC/MS): GC analysis was carried out on Hewlett Packard HP 5890II Gas chromatography fitted with a fused silica DB-Wax column (30 m x 0.25 $\mathrm{mm}$; film thickness: $0.25 \mu \mathrm{m}$ ); carrier gas was nitrogen with linear velocity $38 \mathrm{ml} / \mathrm{min}$, split ratio was adjusted as 30:1. The injector and detector temperature were $250^{\circ} \mathrm{C}$, column temperature was programmed from $80^{\circ} \mathrm{C}$ to $200^{\circ} \mathrm{C}$ at a rate $2^{\circ} \mathrm{C} / \mathrm{min}, 0.5 \mu$ solutions of the essential oil samples in dichloromethane $(1 \%)$ were injected. Quantitative data were obtained from an electronic integration of the flame ionization detector (FID) peak area. GC/MS analysis was performed on HP $5971 \mathrm{~A}$ instrument with MS detector 5890 II of the same company which was operated in El mode $(70 \mathrm{eV}) . \mathrm{GCl}$ MS fitted with a Supelcowax 10 column (60 m x 0.25 $\mathrm{mm}$; film thickness: $0.25 \mu \mathrm{m})$; carrier gas was helium with linear velocity $10 \mathrm{ml} / \mathrm{min}$, split ratio $30: 1$. The injector temperature was $250^{\circ} \mathrm{C}$. The column temperature was programmed from $80^{\circ} \mathrm{C}$ to $120^{\circ} \mathrm{C}$ at a rate $3^{\circ} \mathrm{C} / \mathrm{min}$. The detector temperature was $280^{\circ} \mathrm{C}$. GC condition and capillary column used were as described above, with exception of the carrier gas, which was helium.

Identification of components: The separated components were identified by matching with massspectral library data and by comparison of Kovat's indices with those of authentic components and with published data $[10,11]$.

\section{RESULTS AND DISCUSSION}

Two Artemisia species collected at full flowering and fruiting stage were hydrodistilled and gave the oil yields as shown in Table 1.

Table 1. Essential oil yields of two Artemisia species

\begin{tabular}{lllc}
\hline Plant name & $\begin{array}{c}\text { Date of } \\
\text { collecting }\end{array}$ & $\begin{array}{c}\text { Vegetation } \\
\text { period }\end{array}$ & $\begin{array}{c}\text { Oil yield } \\
\text { (\%) }\end{array}$ \\
\hline A.palustris & $\begin{array}{c}\text { September } \\
2009\end{array}$ & in full bloom & 1.4 \\
A.sericea & July 2008 & in ripe fruits & 0.4 \\
\hline
\end{tabular}

GC and GC-MS analyses led to the detection of 19 constituents, accounting for $89.5 \%$ of A.palustris and 10 constituents, representing $91.9 \%$ of the A.sericea essential oil (Table 2).

The essential oil from the A.palustris was characterized by the presence of monoterpene hydrocarbons, among which (E)- $\beta$-ocimene(trans) and (Z)- $\beta$-ocimene(cis) were dominated (Figure 1). Myrcene, 1,8-cineole, and spathulenol were detected in low percentages. $\beta$-ocimene is one of the most ubiquitous volatiles in floral scents and was found naturally as a mixture of stereoisomers. The trans-isomer is more common and more abundantly emitted in floral volatiles than the cis-isomer $[12,13]$.
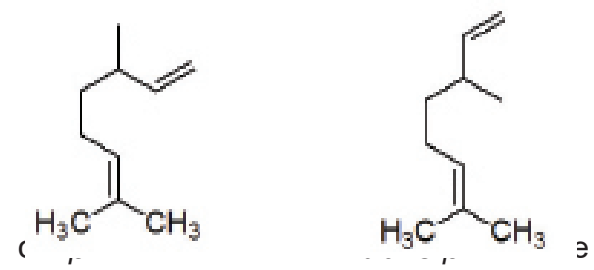

Fig. 1. Structures of two $\beta$-ocimene stereoisomers, cis- and trans- $\beta$-ocimene (also referred to as (Z)- and (E)- $\beta$-ocimene, respectively)

Trans- $\beta$-ocimene occurs in $71 \%$ of the 90 plant families in the list of identified floral-scent compounds compiled by Knudsen et al [13]. Ocimene is widely used as a perfumer agent in the cosmetic industry due to the pleasant aroma [14]. In addition, many other researchers reported about its anti-inflammatory, antifungal and antiviral activities [15-17].

Here, $\beta$-ocimene contents of A.palustris are compared with those data of other Artemisia species, which were reported previously (Table 2).

As can be seen from Table 2, the content of (E)- and (Z)- $\beta$-ocimenes $(11.6 \%$ and $59.1 \%)$ in the essential oil of $A$.palustris was the highest in comparison with other Artemisia species from the Mongolian flora. A noticeable high amount of cis- $\beta$-ocimene $(11.6 \%)$ was found in A.palustris than other Artemisia species due to the remarkable high percentage of trans- $\beta$-ocimene $(59.1 \%)$. It's well known that cis- $\beta$-ocimene is an enzymatically synthesized product from the its trans isomer [13]. However, it was less than the combined amount of $\beta$-ocimene (90\%) in the essential oil of A.palustris from Russia. The observed difference is significant and it could be due to the distinction of geo-ecological conditions.

The essential oil of A.sericea was found to be rich with oxygenated monoterpenoids as 1,8-cineole (25.8\%), borneol $(22.5 \%)$ and camphor (18.8\%), which consequently, the most interesting results of this study. The essential oils of some Artemisia species, such as A.gmelini, A.frigida, A.anethifolia, A.macrocephala, and A.rutifolia, contain similar constituents, which are widely used for the treatment of pneumonia. Obviously, essential oil of $A$.sericea can be used for the same treatment. Essential oils compositions of the Artemisia species are shown in Table 3.

One of the main constituents of the A.sericea is 1,8-cineole, a monoterpene cycle, which has also been named eucalyptol. It is used in flavorings, fragrances, and cosmetics production because of its pleasant spicy and aromatic fragrance. 1,8-cineole also possesses an insecticide activity and medicinal properties for treatment of acute and chronic bronchitis, sinusitis and 
Jawzmaa et al. Mong. J. Chem., 18 (44), 2017, 48-51

Table 2. Chemical constituents in some Artemisia essential oils rich with $\beta$-ocimene

\begin{tabular}{|c|c|c|c|c|c|c|c|}
\hline \multirow[b]{2}{*}{ Constituents } & \multirow[b]{2}{*}{$\mathbf{R I}^{*}$} & \multicolumn{6}{|c|}{ Amount, $\%$} \\
\hline & & $\begin{array}{c}\text { A.palustris } \\
\text { (present study) }\end{array}$ & A.scoparia & A.oxycephala & A.dolosa & A.medioxim & A.aksaiensis \\
\hline$\alpha$-pinene & 939 & 0.4 & 15.2 & 0.7 & 3.8 & 1.3 & 6.5 \\
\hline Camphene & 953 & - & 0.2 & 0.6 & 0.1 & 0.4 & 0.3 \\
\hline Sabinene & 976 & 0.2 & 3.8 & 0.1 & 0.7 & - & 1.8 \\
\hline$\beta$-pinene & 980 & 0.4 & & 0.5 & 1.7 & - & 4.3 \\
\hline Myrcene & 991 & 7.1 & 9.6 & 10.5 & 6.4 & 3.9 & 16.1 \\
\hline$p$-cymene & 1026 & 0.2 & 0.5 & - & 1.0 & 6.6 & 0.7 \\
\hline Limonene & 1031 & 0.1 & 10.2 & 1.2 & 7.0 & - & 8.1 \\
\hline cis- $\beta$-ocimene & 1040 & 11.6 & 1.0 & 0.7 & 0.6 & 7.1 & 1.2 \\
\hline trans- $\beta$-ocimene & 1050 & 59.1 & 29.4 & 15.3 & 16.1 & 13.8 & 13.2 \\
\hline 1,8-Cineole & 1033 & 3.2 & 25.8 & - & 0.2 & - & - \\
\hline cis-sabinenehydrate & 1097 & 0.1 & - & - & 0.8 & - & - \\
\hline Linalool & 1098 & 0.2 & - & - & - & - & 0.3 \\
\hline Camphor & 1144 & 0.6 & - & 0.3 & 0.1 & 1.5 & - \\
\hline Chryzanthenol & 1118 & 1.4 & - & - & - & - & - \\
\hline Terpinen-4-ol & 1177 & 1.0 & 0.2 & - & 1.5 & 0.6 & 1.3 \\
\hline$\alpha$-terpineol & 1189 & - & 0.1 & - & 0.4 & 0.5 & 0.3 \\
\hline$\beta$-caryophyllene & 1418 & 0.6 & 1.6 & 0.7 & 6.9 & - & 2.5 \\
\hline Farnesene & 1458 & 0.3 & 0.4 & 0.3 & - & 1.3 & 0.2 \\
\hline Germacrene-D & 1484 & 0.4 & - & 26.3 & 14.4 & - & 12.3 \\
\hline Spathulenol & 1576 & 2.3 & 0.2 & - & 0.5 & - & 0.7 \\
\hline Caryophyllene oxide & 1586 & 0.3 & 0.1 & - & 0.7 & - & 0.1 \\
\hline
\end{tabular}

${ }^{*}$ RI: Retention index

Table 3. Essential oils constituents of some Artemisia species-rich with 1,8-cineole, borneol, and camphor

\begin{tabular}{|c|c|c|c|c|c|c|c|}
\hline \multirow[b]{2}{*}{ Constituents } & \multirow[b]{2}{*}{ *RI } & \multicolumn{6}{|c|}{ Amount, \% } \\
\hline & & $\begin{array}{l}\text { A.sericea } \\
\text { (present study) }\end{array}$ & A.gmelinii & A.frigida & A.anethifolia & A.macrocepha & A.rutifolia \\
\hline$\alpha$-pinene & 939 & 1.7 & 0.8 & 0.7 & 0.6 & 13.0 & 1.2 \\
\hline Camphene & 953 & 2.2 & 6.1 & 1.3 & 2.7 & 1.2 & 1.3 \\
\hline Sabinene & 976 & - & 0.5 & 0.2 & 0.2 & 7.5 & 0.2 \\
\hline$\beta$-pinene & 980 & - & 0.3 & 0.5 & 0.3 & 6.8 & 0.2 \\
\hline Myrcene & 991 & 2.4 & 0.2 & - & - & 0.6 & 0.1 \\
\hline p-cymene & 1026 & - & 0.6 & 0.6 & 0.2 & 7.1 & 1.4 \\
\hline Limonene & 1031 & - & 0.1 & 0.2 & - & 7.3 & 0.2 \\
\hline 1,8-cineole & 1033 & 25.8 & 20.6 & 27.2 & 1.2 & 22.0 & 25.1 \\
\hline$y$-terpinene & 1058 & - & - & - & - & 15.7 & 0.2 \\
\hline cis-sabinenehydrate & 1097 & - & 0.1 & 0.7 & 0.2 & 0.1 & 0.1 \\
\hline Camphor & 1144 & 18.8 & 40.9 & 35.0 & 26.0 & 31.0 & 21.7 \\
\hline Chryzanthenol & 1118 & - & 4.7 & & 0.2 & & 0.4 \\
\hline Borneol & 1168 & 22.5 & 6.9 & 3.0 & 5.1 & 0.3 & 0.6 \\
\hline Terpinen-4-ol & 1177 & 2.8 & 2.9 & 4.5 & 0.7 & 0.4 & 3.5 \\
\hline$\alpha$-terpineol & 1191 & 1.1 & 1.4 & 2.9 & 0.4 & 0.1 & 1.6 \\
\hline$\beta$-caryophyllene & 1418 & 2.5 & 0.7 & 0.1 & 1.0 & 1.8 & - \\
\hline Germacrene-D & 1484 & 12.1 & 0.5 & 1.5 & - & 3.2 & - \\
\hline
\end{tabular}

${ }^{*} \mathrm{RI}$ : Retention index 
respiratory infections [18]. Borneol and camphor are the other main constituents in the essential oil and both are well-known compounds as an antiseptic, antispasmodic, carminative, cardiac stimulant, respiratory aid, and anthelmintic properties [19]. In addition, in the essential oil of A.sericea, the traces of only two sesquiterpenes, such as germacrene-D (12.1\%) and $\beta$-caryophyllene $(2.5 \%)$ were detected with some other minor monoterpenes including camphene $(2.2 \%)$, terpinen-4-ol $(2.8 \%)$ and myrcene $(2.4 \%)$.

\section{CONCLUSION}

In the study, chemical compositions of the essential oils of A.palustris and A.sericea, from Mongolia were investigated for the first time. The results of the present research have shown that the A.sericea was rich in bioactive oxygenated monoterpenes such as 1,8-cineole, borneol, and camphor, while the A.palustris contained monoterpene hydrocarbons including $(E)-\beta$ ocimene, (Z)- $\beta$-ocimene and myrcene. The essential oil of $A$.sericea could also be used for treatment of asthma, bronchitis, and tuberculosis because of the presence of aromatic alcohols and ketones. Due to the high amounts of $\beta$-ocimene, which is the main component of perfumes and cosmetics, the essential oil of A.palustris can be used as a top-priority natural resource of the $\beta$-ocimene.

\section{ACKNOWLEDGMENT}

Authors would like to thank Prof. Dr. L.D.Radnaeva for her assistance in recording GC and GC-MS analysis of the volatile compounds of A.palustris and A.sericea.

\section{REFERENCES}

1. Pandey A.K., Tripathi N.N. (2011) Aromatic plants of Gorakhpur forest division: Their antimycotic property and medicinal value. Int. J. Pharm. Sci. Rev. Res.,7, 142-147.

2. Abad M.J., Bedoya L.M., Apaza L., Bermejo P. (2012) The Artemisia L. Genus: A review of bioactive essential oils. Molecules, 17, 2542-2566.

3. Shatar S., Altantsetseg Sh. (2011) Chemical composition and technological characteristics of the essential oils of Artemisia species from Mongolian territory. Ekimto, Ulaanbaatar, 78, 96 (in Mongolian).

4. Bora, K.S., Sharma A. (2011) The genus Artemisia: A comprehensive review. Pharm. Biol., 49, 101-109.

5. Tan R.X., Zheng W.F., Tang H.Q. (1998) Biologically active substances from the genus Artemisia. J. Planta Med., 64, 294-302.

6. Markova L.P. (1985) Wild growing useful plants of Flora Mongolia. Nauka, Leningrad, 30-31 (in Russian).
7. Gubanov M.I. (1996) Conspectus of flora Outer Mongolia. Valang, Moscow, 98, 99 (in Russian).

8. Grubov V.I. (1982) Key to the vascular plants. Nauka, Leningrad, 246, 249 (in Russian).

9. Tsevegsuren N., Aitzetmuller K., Bruhl L., Gisela Werner. (2000) Seed Oil Fatty Acids of Mongolian Compositae: The trans-Fatty Acids of Heteropappus hispidus, Asterothamnus centrali-asiaticus, and Artemisia palustris. J. Sep. Sci., 23(5), 360-366.

10. Adams R.P. (2001) Identification of essential oils components by Gas Chromatography/ Mass spectroscopy, Allured Publ, Corp. Carol Stream Illinois, USA.

11. Davies N.W. (1990) Gas chromatographic retention indices of monoterpenes and sesquiterpenes on methyl silicone and Carbowax 20M phases. J. Chromatography, 503, 1-24.

12. Knudsen J.T., Eriksson R., Gershenzon J., Stahl B. (2006) Diversity and Distribution of Floral Scent. Bot. Rev., 72, 1-120.

13. Farre-Armengol G., Filella I., Llusia J., Penuelas J. (2017) Deciphering the biotic and climatic factors that determine floral scents: A meta-analysis of floral volatile emissions. Perspect. Plant Ecol. Evol. Syst., 2017.

14. Kar A. (2003) Pharmacognosy and Pharmacobiotechnology. New age International (P) limited publishers, New Delhi, 295.

15. Golfakhrabadi F., Khanavi M., Ostad S.N., Saeidnia S., Vatandoost H, Abai M.R., et al. (2014) Biological activities and composition of Ferulago carduchorum essential oil. J. Arthropod. Borne Dis., 9(1), 104-15.

16. Monica R.L., Antoine M.S., Rosa T., Giancarlo A.A., Francesco M., et al. (2008) Phytochemical analysis and in vitro antiviral activities of the essential oils of seven Lebanon species. Chem.Biodivers., 5 (3), 461-470.

17. Loizzo M.R., Saab A.M., Tundis R., Statti G.A., Menichini F., et al. (2008) Phytochemical analysis and in vitro antiviral activities of the essential oils of seven Lebanon species. Chem. Biodivers., 5(3), 461-70.

18. Juergens U.R., Dethlefsen U., Steinkamp G., Gillissen A., Repges R., et al. (2003) Antiinflammatory activity of 1,8-cineole (eucalyptol) in bronchial asthma: a double-blind placebo-controlled trial. Resp. Medicine, 97, 250-256.

19. Felter H.W. (1983) The Eclectic Materia Medica, Pharmacology and Therapeutics. Eclectic Medical Publishers, Portland, 1922. 